\title{
Conditioned to eat while watching television? Low-income caregivers' perspectives on the role of snacking and television viewing among pre-schoolers
}

\author{
Rachel E Blaine ${ }^{1,2, *}$, Jennifer Orlet Fisher ${ }^{3}$, Christine E Blake ${ }^{4}$, Alexandria Orloski ${ }^{3}$, \\ Nicholas Younginer ${ }^{4}$, Yasmeen Bruton ${ }^{3}$, Claudia Ganter ${ }^{2}$, Eric B Rimm², Alan C Geller ${ }^{5}$ \\ and Kirsten K Davison ${ }^{2}$ \\ 'Department of Family and Consumer Sciences, California State University, Long Beach, 1250 Bellflower Blvd, FCS \\ FA-15, Long Beach, CA 90840-0501, USA: ${ }^{2}$ Department of Nutrition, Harvard T.H. Chan School of Public Health, \\ Boston, MA, USA: ${ }^{3}$ Department of Public Health, Center for Obesity Research and Education, Temple University \\ College of Public Health, Philadelphia, PA, USA: ${ }^{4}$ Department of Health Promotion, Education, and Behavior, \\ University of South Carolina, Columbia, Columbia, SC, USA: ${ }^{5}$ Department of Social and Behavioral Sciences, \\ Harvard T.H. Chan School of Public Health, Boston, MA, USA
}

Submitted 7 May 2015: Final revision received 3 November 2015: Accepted 30 November 2015: First published online 22 January 2016

\begin{abstract}
Objective: Although television (TV) viewing is frequently paired with snacking among young children, little is known about the environment in which caregivers promote this behaviour. We describe low-income pre-schoolers' snacking and TV viewing habits as reported by their primary caregivers, including social/physical snacking contexts, types of snacks and caregiver rationales for offering snacks. These findings may support the development of effective messages to promote healthy child snacking.

Design: Semi-structured interviews assessed caregiver conceptualizations of pre-schoolers' snacks, purpose of snacks, snack context and snack frequency.

Setting: Interviews occurred in Boston, Massachusetts and Philadelphia, Pennsylvania, USA.

Subjects: Forty-seven low-income multi-ethnic primary caregivers of children aged 3-5 years (92\% female, 32\% Hispanic/Latino, 34\% African American) described their child's snacking in the context of TV viewing.

Results: TV viewing and child snacking themes were described consistently across racial/ethnic groups. Caregivers described snacks offered during TV viewing as largely unhealthy. Labels for TV snacks indicated non-nutritive purposes, such as 'time out', 'enjoyment' or 'quiet.' Caregivers' primary reasons for providing snacks included child's expectations, behaviour management (e.g. to occupy child) and social time (e.g. family bonding). Some caregivers used TV to distract picky children to eat more food. Child snacking and TV viewing were contextually paired by providing child-sized furniture ('TV table') specifically for snacking. Conclusions: Low-income caregivers facilitate pre-schoolers' snacking and TV viewing, which are described as routine, positive and useful for non-nutritive purposes. Messages to caregivers should encourage 'snack-free' TV viewing, healthy snack options and guidance for managing children's behaviour without snacks or TV.
\end{abstract}

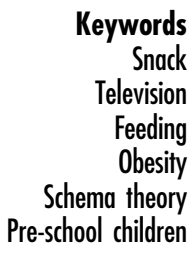

Snack foods are contributing a greater portion of energy to the diets of children than ever before ${ }^{(1)}$. In 2015, children of pre-school age in the USA consumed more than $30 \%$ of their total daily energy in the form of sweet or salty snacks and sugar-sweetened beverages ${ }^{(2)}$, a nearly twofold increase in consumption over the past three decades ${ }^{(3,4)}$. Frequent snacking has been associated with increased energy intake, poor diet quality and other risk factors for childhood overweight and obesity ${ }^{(3,5)}$.
On a usual weekday, the average pre-schooler in the USA watches an estimated $4 \mathrm{~h}$ of television (TV) ${ }^{(6)}$. A review of screen time among children aged 2-6 years found a majority of studies (eleven out of twelve) reported a significant association between TV viewing and adverse dietary outcomes (e.g. increased energy intake, low fruit and vegetable consumption) ${ }^{(7)}$. Another study of 3-5-year-olds found a significant positive association between eating while watching TV and consumption 
of desserts, sugary drinks and snack foods, suggesting a frequent pairing of TV viewing and snacking ${ }^{(8)}$. Aside from measuring exposure to and location of screens in the home, little is known about the environment in which TV viewing and snacking occurs for young children (e.g. who is there) and to what extent caregivers are aware of and/or condoning these concurrent activities $^{(9-11)}$. Many child eating and snacking behaviours emerge prior to school entry, suggesting a need to support caregivers in establishing healthy child snacking habits $^{(12)}$.

Our findings represent a sub-sample from a larger qualitative study designed to explore food parenting practices around child snacking among low-income multiethnic caregivers ${ }^{(13)}$. In the present secondary qualitative analysis, in-depth interviews were used to describe preschool children's snacking paired with TV viewing. Using caregiver descriptions, we identified the social and physical contexts in which child snacking and TV viewing were paired, the types of snacks offered and the reasons why caregivers offered snacks to children watching TV. We also examined differences in the frequency of reported themes between non-Hispanic white, African-American and Hispanic caregivers. Since low-income children of colour are most likely to engage in high levels of TV consumption $^{(6)}$, understanding the context in which snacking occurs and how their caregivers conceptualize snacking and TV viewing is critical to developing tailored family interventions to address early childhood obesity prevention $^{(14-16)}$.

\section{Methods}

\section{Study setting and participants}

We present a secondary analysis of data collected as part of a larger qualitative study of parenting around child snacking ${ }^{(13)}$. The study was conducted in Philadelphia, Pennsylvania and the Greater Boston Area, Massachusetts, USA. Participants were recruited in-person at Special Supplemental Nutrition Program for Women, Infants, and Children (WIC) offices and through flyers posted at WIC offices, playgrounds, Head Start centres and online (e.g. Craigslist.com). Participants were invited to participate in the study if they were at least 18 years of age, a parent or primary caregiver to at least one child aged 3-5 years old, responsible for feeding the child the majority of the time and reported a family income at or below $185 \%$ of the federal poverty level, as identified by participation in or eligibility for government assistance programmes such as WIC. Caregivers were excluded from study participation if their child of interest had a severe food allergy (e.g. nuts), a chronic medical condition (e.g. diabetes) or a developmental disorder that might influence feeding (e.g. cerebral palsy).

Purposive criterion sampling was utilized to obtain a relatively equal distribution of low-income white, Hispanic/ Latino(a) and African-American participants. Reflecting the aims of the larger study, a semi-structured interview guide was used to assess caregivers' conceptualizations of child snacking, purpose for giving snacks, child snacking contexts and frequency of giving different snacks (Table 1). Recruitment concluded in the larger study once we achieved

Table 1 Sample interview guide questions used to conduct in-depth interviews with low-income caregivers regarding child snacking*

1. We are interested in learning more about how you think about [child's name] snack habits and what kinds of things are important when you choose snacks for [him/her]. So, to start, when I say the word 'snack' what do you think of?

Follow-up questions:

What makes something a snack?

How is it different than a meal?

2. So thinking about [child's name], why does [he/she] get snacks?

3. How do you decide what [child's name] eats for a snack?

Follow-up questions:

What role does [child's name] have in this decision?

Are there snacks that you like [child's name] to eat? What things do you do to try to make sure [he/she] eats those kinds of snacks?

Are there snacks that you think [child's name] should eat less often? If yes, what things do you try to do to make sure [he/she] doesn't eat too many of those snacks?

4. How do you decide how much [child's name] eats for a snack?

Follow-up questions:

What role does [child's name] have in this decision?

What things do you do to make sure your child does not eat too much of a particular snack?

5. How do you decide when [child's name] eats a snack?

Follow-up questions:

What role does [child's name] have in this decision?

Tell me about your child's snack habits between dinner and bedtime. What does this look like?

6. In what places or situations does [child's name] usually eat snacks?

Follow-up questions:

Tell me more about [name place/setting using participant phrasing].

Who is typically there when your child has a snack in [name place/situation]?

Why does your child have a snack in [name place/situation]?

*Questions included in this table represent a subset from the larger interview guide. 
saturation in the reported themes across caregivers. Participants were included in the present secondary analysis if they specifically described children's snacking and TV viewing and excluded if they described TV/media only in contexts unrelated to children's snacking (e.g. child's favourite cartoons, parent seeing snacks on TV). Among the sixty participants who completed in-depth interviews, a total of forty-seven discussed TV viewing in the context of child snacking. The study was conducted according to the guidelines laid down in the Declaration of Helsinki and all study procedures were approved by the Institutional Review Boards at the Harvard T.H. Chan School of Public Health and Temple University. Written informed consent was obtained from all participants.

\section{Procedures}

Interviews were conducted by trained interviewers (R.E.B., C.G., A.O. and Y.B.) in either English or Spanish using interview rooms in university facilities. Upon completion of the interviews, participants completed a brief demographic questionnaire assessing caregiver age, education, income, sex, race/ethnicity, child age, number of children in the household and household food security using a six-item short form of the US Household Food Security Survey Module ${ }^{(17)}$. Participants received public transportation fare to cover travel to the interview site and a \$US 45 gift card for participating in the study.

\section{Data analysis}

Interviews were digitally recorded, transcribed into their primary language and verified by each interviewer. In order to ensure contextual accuracy and allow for all data analysis to occur in English, Spanish-language transcripts were translated into English and reviewed a second time by the original English-Spanish bilingual interviewer. A team of three research assistants (R.E.B., N.Y. and A.O.) read and coded transcripts using the qualitative data analysis package NVivo 10 (QSR International, Melbourne, Australia); research assistants did not code transcripts for the interviews that they conducted. Although caregivers were not explicitly prompted to discuss TV viewing and snacking, the role of TV emerged spontaneously in the majority of interviews (forty-seven out of sixty), suggesting it might be an integral component of caregivers' understanding of child snacking. As part of the primary study, all passages in which TV was mentioned in the context of snacking were coded under the theme 'TV', which yielded sufficient data to warrant a secondary analysis.

To guide the coding of TV and snacking-related content among these forty-seven interviews, we used the constant comparative method, a qualitative approach to data analysis which constructs a grounded theory ${ }^{(18)}$. The constant comparative method allows themes to emerge during coding rather than having a set coding scheme prior to analysis ${ }^{(19)}$. We used schema theory as a way to frame emergent themes and categorize the TV viewing context as it relates to child snacking from the perspective of caregivers. In our study, schemas were the mental map of preconceived ideas around child snacking that naturally came to mind for parents, which inform and shape their attitudes and behaviour $^{(20)}$. Examples of caregivers' schemas around snacks might include names/labels for snacks, definitions of snacks or usual contexts in which snacking occurs. Using schema theory allowed us to describe caregiver-identified methods of classifying and categorizing child snacking behaviours using participants' own words in a way that has been used to study child snacking in the past ${ }^{(13,21)}$.

In order to achieve inter-coder agreement, in-depth thematic coding of TV-related passages occurred in the context of discussion, revision and the use of two coders (R.E.B. and C.G.). Transcripts were double coded and through peer debriefing discrepancies in coding were discussed at weekly meetings to clarify interpretation of coded passages and theme definitions. Finalized themes were coded and summarized and matrices run to examine themes across demographic characteristics (e.g. caregiver race/ethnicity, education, food security) using NVivo 10. We used the statistical software package SAS version $9 \cdot 3$ to generate descriptive statistics on demographic characteristics obtained from questionnaires completed by participants, including means and frequency distributions. To assess differences in characteristics between participants who did/did not mention TV we used $\chi^{2}$ tests for categorical variables (e.g. race) and $t$ tests for continuous variables (e.g. age) using a cut-off of $P<0.05$ for significance.

\section{Results}

\section{Participant characteristics}

Participants for this sub-sample ( $n$ 47) were mostly female (92\%) with a mean age of 32 years. The majority of primary caregivers were mothers ( $n$ 42, 89\%), with fathers ( $n 3,6 \%$ ), a grandfather ( $n 1,2 \%)$ and a great aunt ( $n 1,2 \%)$ making up the rest of the sample. Race/ethnicity was reflective of our purposive sampling and included white ( $n$ 16, 34\%), African-American $(n$ 16, 34\%) and Hispanic/Latino ( $n$ 15, $32 \%)$ participants. Most caregivers spoke English as their primary language $(77 \%)$, with only $17 \%$ reported as monolingual in Spanish. Caregivers were fairly evenly divided between being married/cohabiting with a partner (43\%) or single (49\%), with an average of two children per household. Less than half (40\%) of caregivers were employed, with $45 \%$ reporting being out of work. Many caregivers reported experiencing some food insecurity in the past 12 months (47\%), defined as reporting cutting meal sizes, feeling food didn't last, being unable to afford balanced meals or being unable to buy as much food as they should. Caregivers also participated in various public and food assistance programmes (e.g. Supplemental Nutrition Assistance Program). Most caregivers were overweight or obese (68\%) based on BMI calculated from self-reported weight and height. Additional demographic information can be 
found in Table 2 . There were no statistically significant differences in demographic characteristics between participants who did or did not discuss TV during the interviews.

\section{Television viewing as a distinct context for child snacking}

Within the domain of child snacking in the context of TV viewing, three main themes emerged across the forty-seven out of sixty participant interviews that described TV: (i) caregiver labels/categories for child snacks consumed while watching TV; (ii) contexts in which snacking and TV viewing co-occurred; and (iii) caregiveridentified goals for child snacking and TV viewing.

There were few differences in coding categories or domains across demographic characteristics, including racial/ethnic groups. All parents described habitual/routine

Table 2 Demographic characteristics of participants: low-income caregivers $(n 60)$ of children aged $3-5$ years from the Northeastern USA

\begin{tabular}{|c|c|c|c|c|}
\hline \multirow[b]{2}{*}{ Demographic characteristic } & \multicolumn{2}{|c|}{ All interviewed } & \multicolumn{2}{|c|}{ Discussed TV and snacking } \\
\hline & $n$ or Mean & $\%$ or SD & $n$ or Mean & $\%$ or SD \\
\hline Total participants & 60 & $100 \cdot 0$ & 47 & $78 \cdot 3$ \\
\hline \multicolumn{5}{|l|}{ Sex } \\
\hline Female & 56 & $93 \cdot 3$ & 43 & 91.5 \\
\hline Male & 4 & $6 \cdot 7$ & 4 & 8.5 \\
\hline Caregiver age in years (mean, SD) & $31 \cdot 2$ & 8.4 & 31.9 & 9.2 \\
\hline \multicolumn{5}{|l|}{ Relationship to child } \\
\hline Mother & 55 & 91.7 & 42 & 89.4 \\
\hline Other & 5 & $8 \cdot 3$ & 5 & $10 \cdot 6$ \\
\hline \multicolumn{5}{|l|}{ Race } \\
\hline White & 17 & $28 \cdot 3$ & 16 & 34.0 \\
\hline African American & 23 & $38 \cdot 3$ & 16 & $34 \cdot 0$ \\
\hline Hispanic/Latino & 20 & $33 \cdot 3$ & 15 & 31.9 \\
\hline \multicolumn{5}{|l|}{ Primary language(s) spoken } \\
\hline Only/mostly English & 45 & $75 \cdot 0$ & 36 & $76 \cdot 6$ \\
\hline Both English and Spanish equally & 3 & $5 \cdot 0$ & 3 & $6 \cdot 4$ \\
\hline Only/mostly Spanish & 12 & $20 \cdot 0$ & 8 & $17 \cdot 0$ \\
\hline \multicolumn{5}{|l|}{ Education } \\
\hline Less than high school & 10 & $16 \cdot 6$ & 5 & $10 \cdot 6$ \\
\hline High-school graduate/GED & 18 & 31.7 & 15 & 31.9 \\
\hline Technical school/some college & 23 & $38 \cdot 3$ & 18 & 38.3 \\
\hline College graduate or greater & 9 & $15 \cdot 0$ & 9 & $19 \cdot 1$ \\
\hline \multicolumn{5}{|l|}{ Employment } \\
\hline Employed & 19 & 35.2 & 17 & 39.5 \\
\hline Self-employed & 3 & $5 \cdot 6$ & 3 & $7 \cdot 0$ \\
\hline Out of work more than 1 year & 14 & $25 \cdot 9$ & 11 & $25 \cdot 6$ \\
\hline Out of work less than 1 year & 14 & $25 \cdot 9$ & 8 & 18.6 \\
\hline Other & 4 & 7.4 & 4 & $9 \cdot 3$ \\
\hline \multicolumn{5}{|l|}{ Full-time student } \\
\hline Yes & 20 & $33 \cdot 3$ & 18 & 38.3 \\
\hline No & 40 & $66 \cdot 7$ & 29 & $61 \cdot 7$ \\
\hline \multicolumn{5}{|l|}{ Marital status } \\
\hline Married or living with partner & 23 & $38 \cdot 3$ & 20 & $42 \cdot 6$ \\
\hline Divorced/separated & 5 & $8 \cdot 3$ & 4 & 8.5 \\
\hline Single & 32 & $53 \cdot 3$ & 23 & 48.9 \\
\hline \multicolumn{5}{|l|}{ Weight status* } \\
\hline Underweight & 2 & $3 \cdot 3$ & 1 & $2 \cdot 1$ \\
\hline Normal weight & 17 & $28 \cdot 3$ & 14 & 29.8 \\
\hline Overweight & 11 & $18 \cdot 3$ & 9 & $19 \cdot 2$ \\
\hline Obese & 30 & $50 \cdot 0$ & 23 & 48.9 \\
\hline \multicolumn{5}{|l|}{ Experienced food insecurity in past 12 months $\dagger$} \\
\hline Yes & 26 & $43 \cdot 3$ & 22 & $46 \cdot 8$ \\
\hline No & 34 & $56 \cdot 7$ & 25 & 53.2 \\
\hline \multicolumn{5}{|l|}{ Participated in assistance programmes } \\
\hline WIC & 42 & $70 \cdot 0$ & 33 & $70 \cdot 2$ \\
\hline Food Stamps/SNAP/EBT & 48 & $80 \cdot 0$ & 38 & 80.9 \\
\hline Free/reduced-price school meals & 28 & $46 \cdot 7$ & 20 & $42 \cdot 6$ \\
\hline Head Start & 21 & $35 \cdot 0$ & 16 & 34.0 \\
\hline Age of child in years (mean, SD) & 3.9 & 0.8 & 3.9 & 0.8 \\
\hline Number of children in household (mean, SD) & 2 & 1.0 & 2 & 1.0 \\
\hline
\end{tabular}

TV, television; GED, General Education Development; WIC, Special Supplemental Nutrition Program for Women, Infants, and Children; SNAP, Supplemental Nutrition Assistance Program; EBT, Electronic Benefit Transfer.

Data presented are $n$ and \% unless indicated otherwise.

*Weight status based on self-reported BMI.

†Assessed using the six-item short form of the US Household Food Security Survey Module ${ }^{(17)}$. 
snacking and TV viewing occasions, and a majority of participants described specific scenarios in which their child ate snacks while watching TV ( $n$ 31). Child snacking and TV viewing frequently co-occurred in the context of a predictable, daily routine of the child snacking with the TV on $(n$ 13):

'She only wants to go in front of the TV when she has snacks.' (Hispanic mother of a 4-year-old girl)

'When he's watching like cartoons, he'll eat snacks.' (White mother of a 3-year-old boy)

'She knows her snack-TV time.' (White mother of a 4-year-old girl)

In the context of these eating episodes, many caregivers ( $n$ 10) identified that the child was distracted while watching TV and consuming his/her snacks:

'Like, she could eat the whole little box of Oreos - just sitting there by herself like, sitting there - like, [when] she would watch cartoons.' (Hispanic mother of a 4-year-old girl)

'Snack is different from a meal because, you know, they can sit in front of the TV and eat a snack. But rather than when I feed 'em their meal, they got to stay at the table, no TV on, no pencil and paper at the table.' (African-American father of a 3-yearold boy)

Some caregivers described children expressing resistance to consuming snacks in locations away from the TV, such as the kitchen table $(n$ 4):

'I say come sit at the table, and he won't. He won't sit to eat here. It's almost as if he's conditioned to watch TV and eat.' (White mother of a 4-year-old boy)

'Because when I serve her [snacks] ... she doesn't like sitting at the table, she has a blanket and there she sits on the floor and she watches TV.' (Hispanic mother of a 5-year-old girl)

Characteristics of snacks consumed by children when watching television

More than half ( $n$ 25) of caregivers discussed specific snacks that their pre-schoolers consumed when watching TV. They described a broad range of snack choices offered, ranging from fruits and vegetables to cookies and chips. Caregivers used a variety of labels to describe these snacks offered during TV viewing, with categories including healthfulness of food ('good for her'; 'junk food'), taste ('things on the sweet side'), size ('something small'; 'little snacky foods') and frequency ('foods he has on special occasions'; 'things that we don't eat so often'). Overall, more caregivers described snacks consumed when watching TV as unhealthy than healthy, with the word 'junk' being used most frequently. Additionally, many caregivers used non-nutritive labels for the foods to indicate their purpose ('calm-her-down snacks'; 'time-out snacks'; 'a fun little thing').

\section{Physical and social contexts}

Caregivers often referred to the physical or environmental context in which snacking and TV viewing took place ( $n$ 17), mentioning that children frequently snacked in a room of the house where the TV was located (e.g. living room, parlour, family room). Only one participant described her child snacking in his bedroom while watching TV. Among those who described the snacking and TV viewing environment, more than half described the use of specific furniture to facilitate snacking, such as a child-sized 'TV table' or 'bean bag' used primarily or exclusively for eating in front of the TV:

'He eats [snacks] in front of the television. So he has this little table and chairs and usually I join him, in front of the TV.' (White mother of a 3-year-old boy)

'I pull the TV table out when she's having snacks.' (White mother of a 4-year-old girl)

When describing the snacking and TV viewing context, many participants provided details about social situations that children experienced around snacking in front of the TV. Some participants described their child snacking by themselves ( $n$ 8): 'I'm nearby, but you know, as long as I monitor it, he's on his own.' However, more frequently, children were described as having snacks alongside other family members (i.e. parents, siblings, grandparents) or friends while watching TV ( $n$ 18). In most cases participants described themselves as the primary person participating in snacking while watching TV with their child:

'I eat it with her. Like we have snack time together while we're watching cartoons.' (African-American mother of a 4-year-old girl)

Caregiver rationales for giving children snacks while watching television

Among those who described TV viewing and snacking, many participants ( $n$ 26) provided at least one rationale for offering their child snacks specifically when watching TV. Four key reasons were provided by caregivers: (i) children expect snacks with TV; (ii) snacking and TV watching promotes social interaction; (iii) behaviour management; and (iv) to encourage intake of more food. Most caregivers provided multiple rationales for encouraging children to eat snacks while watching TV.

A primary rationale that participants gave for allowing children to have snacks and watch TV was that the TV being on prompted children to ask for expected snacks (n 13):

'So usually it's TV and [then], "I want a snack".' (White mother of a 4-year-old girl) 
'I think they ask more for the junk foods 'cause they see other kids eating a lot of it. You see it a lot on TV, on commercials, so they ask for it..." (AfricanAmerican mother of a 4-year-old girl)

In some cases, caregivers discussed their child requesting snacks even in the absence of hunger:

'Well, she's just usually not hungry she'll just say she just wants it because someone else has it. So she'll sit in front of the TV with a bunch of apples. Like she'll, she'll want something like that to watch TV.' (White mother of a 4-year-old girl)

Caregivers also cited social motivation ( $n$ 11) for child snacking and TV time, describing a desire to bond and spend time as a family together. Caregivers indicated that snacks with TV helped to bring family members together to form positive memories:

'We tend to sometimes have snacks together. Sit down, me and his brother, and just talk or if we're watching a movie we'll have a little bit of popcorn. So it's more like a bonding type of thing for us, too.' (White mother of a 4-year-old boy)

'I think of like visiting my papa where he lives, like there's just this cute picture of the two of them watching TV eating doughnuts..." (White mother of a 3-year-old girl)

'When we all seated at home in the family room to watch a movie, that's when he asks [for snacks]. Or we may have chips, or cookies or fruits. We sit down to watch a movie together and we nibble on fruit that's for everyone.' (Hispanic mother of a 4-yearold boy)

Additionally, caregivers described snacking and TV as a way to manage active pre-schoolers' behaviour, either as a way to occupy their child ( $n$ 11) or as a way to achieve some free time to do other things around the house $(n 5)$ :

'Like if I'm cleaning or something or I got some paperwork to fill out or work to do around the house I just sit him in front of the TV and he eat like, he will nibble on like fruit, vegetables, anything like that.' (African-American mother of a 3-year-old boy)

'And keeping her busy is more of sitting down watching TV like the popcorn, the waters, the hard pretzels, candy and just to keep busy... I mean there's really no nutrition, but it keeps her occupied.' (White mother of a 5-year-old girl)

'...I just to try to keep her quiet and you know kinda keep, like I said, happy. I'll just give her a couple of cookies if she's sitting down and relaxing and watching something.' (White grandfather of a 4-yearold girl)
A smaller number of caregivers ( $n$ 4) explained that they used TV viewing as a time to distract their child in order to get them consume more food. These caregivers all described their pre-schoolers as 'picky' and felt that the distraction posed by the TV offered an important time to increase their child's intake of healthy foods:

'I can give her the more healthy options when she's watching TV because she's kind of distracted by that and like, you know, not thinking of like the candy bar that she probably would want you know, if she wasn't distracted by having the TV.' (White mother of a 4-year-old girl)

'...it goes back to the distraction thing with him. It's another - it's a good way to have him, you know, enjoying the cartoons as well as getting him to have some nourishment.' (White mother of a 3-yearold boy)

\section{Discussion}

The present study is the first to examine low-income caregivers' perceptions and experiences of pre-schoolers' snacking and TV viewing behaviours, including contextual descriptions of child snacking episodes, caregiver-identified labels for 'TV snacks' and rationales for promoting simultaneous snacking and TV viewing among children. We found in a subset of interviews ( $n$ 47) that TV viewing was a routine context within which pre-schoolers receive and consume snacks, suggesting that TV viewing was a component of low-income white, African-American and Hispanic/Latino caregivers' conceptualizations of child snacking. Across racial/ethnic groups, caregivers appeared to accommodate snack-TV routines by consistently offering snack foods whenever the child viewed TV or by providing child-sized eating furniture in rooms with TV.

Although the role of TV has not previously been described, previous studies of low-income caregivers have indicated that eating occasions are considered important for child socialization and that snack foods are commonly described as tools for behaviour management ${ }^{(22,23)}$. Our findings build upon existing literature, presenting nuanced caregiver attitudes regarding pre-schoolers' snacking and TV viewing, a pairing described as routine, positive and useful with an emphasis on non-nutritive motivations including family bonding. Low-income caregivers' feeding decisions may occur in the context of a complex interplay between balancing home life stress and environmental constraints $^{(24,25)}$. When resources are limited, TV and lowcost snacks may be more available options for family time compared with a trip to the movie theatre ${ }^{(26,27)}$. Limited income is an important consideration within our sample, as nearly half of participants reported some type of recent food insecurity. Additionally, demanding or stressful jobs may lead tired caregivers to seek out positive 
opportunities for children to unwind quietly with a snack and cartoon programme, which are perceived as educational and useful for learning English ${ }^{(28-31)}$. Understanding these values is essential to identifying ways to support caregivers in adopting healthful practices around snacking and media use.

In our study caregivers described two key snacking and TV viewing patterns that may contribute to excessive weight gain in childhood: using food to manage behaviour and encouraging children to eat in the absence of hunger, themes identified in other snack feeding literature ${ }^{(23)}$. Labels used to describe the snacks eaten during TV viewing often include a desired outcome rather than nourishing attribute, such as giving a child a snack with TV for 'enjoyment' or 'relaxation'. In children for whom TV is a prompt to eat in order to be quiet or a reward behaviour, increased opportunities for snacking may lead to overeating, as studies have observed some pre-schoolers consume large food portions without limiting their energy intake at later meals ${ }^{(32,33)}$. Distracted or mindless eating while watching TV may also contribute to significantly higher intake of energy per eating episode and reduced satiety in children, possibly leading to future overeating ${ }^{(34,35)}$.

Our findings should be considered in the context of pre-schoolers' potential frequency of exposure to TV snacking cues, as pre-schoolers watch nearly double the American Academy of Pediatrics' recommended limit of $2 \mathrm{~h}$ daily ${ }^{(6,36)}$. The inherent context of TV viewing, which includes positive social time, energy-dense foods and comfortable bean bags or TV tables, may stimulate children's intake and reinforce established routines. In the past, experimental work has demonstrated that repeated cues to eating in the form of audio and visual stimuli can override children's sense of fullness after consuming a snack and cause them to continue to consume significantly more energy than when the stimuli are not present ${ }^{(37)}$. Although a few caregivers in our study described offering healthy snack options when children viewed TV, the majority described TV-viewing snacks as 'junk', 'fun' or 'special' foods like cookies or chips. Since many of these commonly consumed snacks are energy-dense ${ }^{(38)}$, pairing such foods with a routine activity like TV viewing may increase children's likelihood of exceeding their daily energy needs. In addition to increased sedentary time and exposure to food marketing, it is not surprising that greater levels of TV viewing have been associated with elevated BMI $Z$-scores in pre-schoolers ${ }^{(10)}$.

To better communicate existing American Academy of Pediatrics' guidelines to caregivers, more attention needs to be paid to the pairing of TV viewing and child snacking. In one study examining TV viewing among pre-schoolers, low-income parents reported significantly less confidence in limiting their child's TV time or finding other activities to occupy their children when compared with higher-income parents ${ }^{(28)}$. Since caregivers described encouraging child snacking paired with TV viewing, messages to caregivers should encourage 'snack-free' TV viewing for children, healthy snack options and guidance for managing children's behaviour without using snacks or TV. Many caregivers reported engaging in snacking and TV viewing along with their children, and may also benefit from increased skill building around setting an example by turning off the TV when food is served and saving 'fun' snacks for special occasions where they are appreciated.

Our study has some limitations. Our findings are only reflective of a sample of caregivers who described children's TV viewing in the context of snacking without prompting. Thus, we are not able to compare them with caregivers who either did not mention their children snacking and watching TV, or those caregivers who no do permit or promote such behaviours. Due to the sample size and nature of qualitative research, our findings may not be generalizable for all low-income caregivers of pre-schoolers. However, one benefit of using a purposive criterion sample was our ability to examine differences in attitudes and beliefs among racial/ethnic groups and to study caregiver beliefs in depth by using an interview format that utilized open-ended questions. Since our findings regarding pre-schooler snacking and TV viewing were emergent, there may be other unmeasured attitudes/ beliefs held by caregivers. Nevertheless, we believe that the frequency with which various TV and snacking behaviours were mentioned indicates that the topic was important to our population and that rich qualitative data can be used to inform the development of messages to promote healthy child snacking.

Little has been known about the environment in which children are snacking and viewing TV and the extent to which caregivers are aware of and/or condoning these behaviours ${ }^{(9-11)}$. Our study provides valuable insight into low-income caregivers' perspectives around child snacking and helps to shed light on possible areas for future inquiry. More dialogue with caregivers is needed to identify appropriate messages that address child snacking and appropriate limits on screen time. Observational studies should examine the frequency of child snacking and TV viewing in the context of parent roles and expectations. Helping caregivers identify strategies to promote healthy child snacking during TV viewing and reduce time spent snacking in front of screens may be important behavioural targets for future childhood obesity prevention interventions serving low-income families.

\section{Acknowledgements}

Financial support: This project was supported the National Institute of Child Health and Human Development (grant number NIH R21 HD074554) and in part by funds from an unrestricted educational grant from ConAgra Foods Foundation to Temple University. ConAgra Foods Foundation had no role in the design, analysis or writing of this article. R.E.B., a doctoral candidate, was supported by a National Institutes of Health (NIH) Doctoral 
Training Grant in Cancer Epidemiology (grant number T32 CA 0900) at the Harvard T.H. Chan School of Public Health. The contents of this article are solely the responsibility of the authors and do not necessarily represent the official views of the National Institute of Child Health and Development or the NIH. Conflict of interest: None. Authorship: Contributors R.E.B., J.O.F., C.E.B., A.O., N.Y., E.B.R., A.C.G. and K.K.D. contributed to the design of the study. R.E.B., A.O., N.Y., Y.B. and C.G. participated in data collection. R.E.B. drafted the manuscript and conducted initial data analysis. All authors contributed to the writing and interpretation of findings and approved the final version of the manuscript.

\section{References}

1. Piernas C \& Popkin BM (2010) Trends in snacking among US children. Health Aff (Millwood) 29, 398-404.

2. Bleich SN \& Wolfson JA (2015) US adults and child snacking patterns among sugar sweetened beverage drinkers and non-drinkers. Prev Med 72, 8-14.

3. Larson N \& Story M (2013) A review of snacking patterns among children and adolescents: what are the implications of snacking for weight status? Child Obes 9, 104-115.

4. Ford CN, Slining MM \& Popkin BM (2013) Trends in dietary intake among US 2- to 6-year-old children, 1989-2008. J Acad Nutr Diet 113, 35-42.

5. Shroff MR, Perng W, Baylin A et al. (2014) Adherence to a snacking dietary pattern and soda intake are related to the development of adiposity: a prospective study in school-age children. Public Health Nutr 17, 1507-1513.

6. Tandon PS, Zhou C, Lozano P et al. (2011) Preschoolers' total daily screen time at home and by type of child care. J Pediatr 158, 297-300.

7. Ford C, Ward D \& White M (2012) Television viewing associated with adverse dietary outcomes in children ages 2-6. Obes Rev 13, 1139-1147.

8. Erinosho TO, Beth Dixon L, Young C et al. (2013) Caregiver food behaviours are associated with dietary intakes of children outside the child-care setting. Public Health Nutr 16, 1263-1272.

9. Maitland C, Stratton G, Foster S et al. (2013) A place for play? The influence of the home physical environment on children's physical activity and sedentary behaviour. Int J Behav Nutr Phys Act 10, 99.

10. Cox R, Skouteris H, Rutherford L et al. (2012) Television viewing, television content, food intake, physical activity and body mass index: a cross-sectional study of preschool children aged 2-6 years. Health Promot J Aust 23, 58-62.

11. De Jong E, Visscher T, HiraSing R et al. (2013) Association between TV viewing, computer use and overweight, determinants and competing activities of screen time in 4-to 13-year-old children. Int J Obes (Lond) 37, 47-53.

12. Rollins BY, Loken E \& Birch LL (2010) Stability and change in snack food likes and dislikes from 5 to 11 years. Appetite 55, 371-373

13. Davison KK, Blake CE, Blaine RE et al. (2015) Parenting around child snacking: development of a theoretically-guided, empirically informed conceptual model. Int J Behav Nutr Phys Act 12, 109.

14. Taveras EM, Hohman KH, Price S et al. (2009) Televisions in the bedrooms of racial/ethnic minority children: how did they get there and how do we get them out? Clin Pediatr (Phila) 48, 715-719.

15. Taveras EM, Gillman MW, Kleinman K et al. (2010) Racial/ ethnic differences in early-life risk factors for childhood obesity. Pediatrics 125, 686-695.
16. Flores G \& Lin H (2013) Factors predicting severe childhood obesity in kindergarteners. Int J Obes (Lond) 37, 31-39.

17. Blumberg SJ, Bialostosky K, Hamilton WL et al. (1999) The effectiveness of a short form of the Household Food Security Scale. Am J Public Health 89, 1231-1234.

18. Grove RW (1988) An analysis of the constant comparative method. Int J Qual Stud Educ 1, 273-279.

19. Taylor S \& Bogdan R (1984) Introduction to Research Methods. New York: Wiley.

20. Nishida H (2005) Cultural schema theory. In Theorizing About Intercultural Communication, pp. 401-418 [WB Gudykunst, editor]. Thousand Oaks, CA: SAGE Publications, Inc.

21. Blake CE, Bisogni CA, Sobal J et al. (2007) Classifying foods in contexts: how adults categorize foods for different eating settings. Appetite 49, 500-510.

22. Fisher JO, Wright G, Herman A et al. (2013) Snacks are not food: low-income mothers' definitions and feeding practices around child snacking. FASEB J 27, 231.1.

23. Fisher J, Wright G, Herman A et al. (2015) 'Snacks are not food'. Low-income, urban mothers' perceptions of feeding snacks to their preschool-aged children. Appetite 84, 61-67.

24. Zsembik BA \& Fennell D (2005) Ethnic variation in health and the determinants of health among Latinos. Soc Sci Med 61, 53-63.

25. Suglia SF, Duarte CS, Chambers EC et al. (2012) Cumulative social risk and obesity in early childhood. Pediatrics $\mathbf{1 2 9}$, e1173-e1179.

26. Adachi-Mejia AM, Longacre MR, Gibson JJ et al. (2007) Children with a TV in their bedroom at higher risk for being overweight. Int J Obes (Lond) 31, 644-651

27. Haines J, O’Brien A, McDonald J et al. (2012) Television viewing and televisions in bedrooms: perceptions of racial/ ethnic minority parents of young children. J Child Fam Stud 22, 749-756.

28. Njoroge WF, Elenbaas LM, Garrison MM et al. (2013) Parental cultural attitudes and beliefs regarding young children and television. JAMA Pediatr 167, 739-745.

29. Jordan AB, Hersey JC, McDivitt JA et al. (2006) Reducing children's television-viewing time: a qualitative study of parents and their children. Pediatrics 118, e1303-e1310.

30. Lindsay AC, Sussner KM, Greaney ML et al. (2009) Influence of social context on eating, physical activity, and sedentary behaviors of Latina mothers and their preschool-age children. Health Educ Behav 36, 81-96.

31. Davis RE, Cole SM, Reyes LI et al. (2015) 'It hurts a Latina when they tell us anything about our children': implications of Mexican-origin mothers' maternal identities, aspirations, and attitudes about cultural transmission for childhood obesity prevention. Child Obes 11, 608-615.

32. Fisher JO \& Kral TV (2008) Super-size me: portion size effects on young children's eating. Physiol Behav 94, 39-47.

33. Mrdjenovic G \& Levitsky DA (2005) Children eat what they are served: the imprecise regulation of energy intake. Appetite 44, 273-282.

34. Boulos R, Vikre EK, Oppenheimer S et al. (2012) ObesiTV: how television is influencing the obesity epidemic. Physiol Behav 107, 146-153.

35. Marsh S, Ni Mhurchu C \& Maddison R (2013) The nonadvertising effects of screen-based sedentary activities on acute eating behaviours in children, adolescents, and young adults. A systematic review. Appetite 71, 259-273.

36. Strasburger VC, Hogan MJ, Mulligan DA et al. (2013) Children, adolescents, and the media. Pediatrics 132, 958-961.

37. Birch L, McPhee L, Sullivan S et al. (1989) Conditioned meal initiation in young children. Appetite 13, 105-113.

38. Patro B \& Szajewska H (2010) Meal patterns and childhood obesity. Curr Opin Clin Nutr Metab Care 13, 300-304. 